\title{
Reflective narration: Impact of Observing Young children's use of iPad on Lecturers' Teaching Approaches in Higher education
}

\begin{tabular}{c|c} 
Gretchen Geng & Leigh Disney \\
School of Education, Charles Darwin & School of Education, Charles Darwin \\
University, Australia & University, Australia \\
gretchen.geng@cdu.edu.au & leigh.disney@cdu.edu.au \\
\hline
\end{tabular}

Keywords: reflection, iPad, higher education, children, teaching approaches

\begin{abstract}
People engage in learning to produce knowledge, and learning can be undertaken outside learning institutions, involving interaction between different people among social communities. Learning can happen both publically and privately through reflection time. Likewise, education cannot always be conducted within certain hours or certain places. It can happen anytime, with anyone within any culture. This paper highlights the perceptions and experience of two higher education lecturers in teacher education, following observations of pedagogical practices and philosophies of two young children playing with an iPad. Acknowledging the importance of reflective practice in teaching, we use reflective narration to illustrate the influence of our observations of young children's playing with this technology (an iPad) upon our own teaching approaches in higher education settings. Following this we outline several future research interests into use of gestural interface technology in teaching strategies. Lecturers in higher education, particularly educators in information technologies and early childhood education, may find this paper interesting as a stimulus to their own reflection that might improve their own teaching outcomes.
\end{abstract}




\section{Gretchen's reflection}

10.35am (November 18, 2013):

"Come on mom, I would like to show you the new games. They are awesome!"

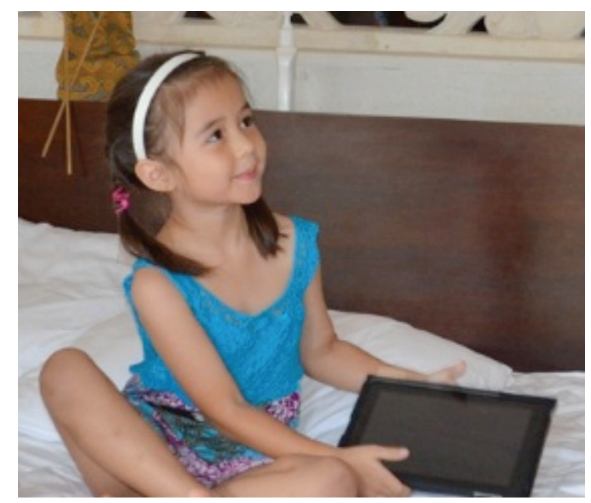

Brooke eagerly brought her iPad in front of me and started to show the new game "Bugs and Buttons 2". The game started with a group of ants in a line marching across the screen as Brooke swept away foreign objects for the ants so that they could keep on their path. Brooke laughed and hummed along with the game's exceedingly catchy music.

This is one typical example of my days with my daughter Brooke, who is 5 years old. Looking at her engagement with the iPad I decided that I should purchase her a greater range of appropriate iPad games as one of her Christmas presents. As a mother of two girls and a lecturer in education, I value education in my children's life. My children are what Tomita (2009) considers to be learners born into a world of technology. With the popularity of ICTs, students start to use different technologies to learn, research and communicate with each other. For example, in many school contexts, mobile phones, MP3 players and other similar digital devices have become acceptable technology for students to use. In particular, there are more than 6.8 billion mobile phones in the world in 2013 (International Telecommunication Union, 2013), and one major group of users are school students.

As a traditionally trained teacher, I have learned that technology can be used in classroom teaching. I chose educational computing as one of my majors and during the last ten to twenty years, I have experienced technologies used in my daily life as well as in my teaching career. I explored many different kinds of technologies and their use within classroom settings for pre-service teachers and was always fascinated by the use of technologies in educational settings. I chose to research online learning as my PhD project, which I completed in 2007, and I presented some major findings from my research:

It was found that (a) teachers could assist students by using instructional resources such as graphics, sounds, and animations; (b) effective student-teacher relationship was a critical success factors in students' online learning; (c) teachers needed to provide feedback or assistance to help the students improve their learning-to-learn skills, and independent learning skills; and (d) students also reported that these factors assisted in developing problem-solving skills, reaching deeper understandings, and achievement in successful online learning. (Geng, Au \& Yates, 2007) 
After I completed my PhD, my passion towards the use of technology in classroom teaching has been developed. I have started teaching Information and Communication Technology (ICT) in pre-service teacher education programs. As required by Australian Professional Standards for Teachers in Australian Institute for Teaching and School Leadership (AITSL, 2014), graduate teachers shall possess the requisite knowledge and skills to plan for and manage learning programs for their students, from early childhood to high schooling. Therefore, a graduate teacher should know the content and how to teach it (AITSL, 2014), and more specifically standard 2.6 requires a graduate teacher to implement teaching strategies for using ICT to expand curriculum learning opportunities for students.

In teaching ICT in education, my teaching and researching focus has also shifted from using computer technologies to mobile learning. I started to research mobile learning since 2007. Different from computer technologies, mobile learning allows users to try more hand-held small and portable devices, such as mobile phones, computer laptop and tablets.

As my teaching target group of students is mainly pre-service teachers, who are mostly over 18 years old, I have never directly taught in educational settings with children younger than 5 years before. This puts me into a dilemma as to how I am going to test and decide upon the appropriateness of the use of mobile technologies with young children, in particular my own children!

\section{Leigh's Reflection}

Before my life as a lecturer in the field of early childhood, I was an undergraduate student studying early childhood at the University of South Australia during the early to mid-2000's. My studies would not have been attainable without the use of technology and educational media and much of my entertainment also revolved around the use of emergent technologies. Yet in my professional work as a qualified child care worker during that period I actively distanced myself from the use of technology with the children to the point that I would suggest that the use of technology made me feel uncomfortable and that I considered educational media (e.g. T.V's, computers) as "lazy" teaching compared to more appropriate early childhood experiences. This feeling that somehow technology and early childhood learning are at opposite ends of a spectrum of experience is not new and I truly was not alone in that feeling. Early childhood educators feel a certain way about the appropriate pedagogies and tools to use with young children and I can assure you there is a strong undercurrent that anything with a microchip and processor does not fit "developmentally appropriate practice"! In my experience the developing preschool child has great difficulty in dealing with traditional mouse and keyboards computer and one-way communication devices such as television and DVDs did not seem like engaging or beneficial learning tools. Child care centres in the early 2000's had limited technology in them and there was not a strong undercurrent to fund any new educational media devices.

So when did my comprehension of the value of technology change and how did I grow to become a researcher and lecturer who has 'particular interests' in the use of educational media with preschool children? It started when I met my wife and current research partner Gretchen. The first time she visited me in my child care setting she asked:

Gretchen: Why there is no computer in your classroom?

Leigh: I had one before, but it was broken and I had to get rid of it.

Gretchen: Why?

Leigh: Because the technology is not developmentally appropriate for little

fingers. Computers, keyboard and mouse are not designed for young children to use easily. 


\begin{abstract}
Gretchen: Mmmm... This is interesting. Why do you not use an Interactive Whiteboard then?

Leigh: It's too expensive for our centre and we have more appropriate early childhood resources to buy with the funding.
\end{abstract}

\title{
Gretchen (encouraging): How about mobile learning technologies? Leigh: Mobile what?
}

Gretchen's area of expertise was the use of technology and mobile learning within higher education settings. Whilst I had been an undergraduate student I had somewhat taken for granted the technology around me that allowed me to gather information and effectively demonstrate my knowledge. After meeting Gretchen and reading her work I was able to view my own education from a different perspective. Around the same time as meeting Gretchen I moved from a child care setting to working in a primary school.

Having a new found appreciation for the value of technology and educational media I actively made efforts to incorporate the use of technology with young children. In addition to my own willingness to embrace technology I was now in an educational setting that encouraged the use of technology and with children who developmentally were capable of using such technologies. For the first time in my professional life I felt not a responsibility but a willingness to use technology as an appropriate learning tool for young children. In particular I found the use of interactive whiteboards to be revolutionary and it opened up a myriad of opportunities to engage learners with a range of learning dispositions and styles. However one term into my teaching experience my wife fell pregnant and changes were coming!

In 2008 our first child, Brooke was born and my understanding of children would be changed forever! When one is charged with the daily care and education of your own child, a child that you are responsible for twenty-four hours a day, seven days a week you gain an appreciation of the diversity in care and education you need to deliver for that child in order for them to reach their potential. When working with other people's children in child care settings I often looked at my role to provide them with experiences that I felt met their learning style and potentially expose them to experiences they may not be getting at home. However, with my own child (for whom I was a stay at home father for), my wife and I were her primary and only source of education. Hence we felt a responsibility to expose Brooke to a wide variety of experiences and learning tools. Much of my experience as a qualified child care worker came through and I provided Brooke with a wide variety of sensory and developmentally appropriate play. This was also a wonderful learning experience for my wife who had very little understanding of young children and their education. She was able to gain an appreciation of the nuances of early childhood and the ways in which young children learn and develop. Similarly I incorporated Gretchen's deep knowledge of mobile learning and technology to provide Brooke with appropriate technological experiences. However we were still finding that much of the technology for children was still too difficult for her to use and was often still one directional, hence limited true engagement and learning. This all changed in December of 2009, Gretchen gets her iPad!

The iPad was the first mobile gestural interface that we had purchased and exposed Brooke to and it was evident from day one that she could not only navigate appropriate software using the iPad, but do it easily with a high level of engagement and interactivity, especially when compared to the one way interaction of a television screen and the fine motor and cognitive developmental inappropriateness of mouse and keyboard devices. For the first time she could use her fingers as the sole interactive tool, this allowed her to control the device and after a few days Leigh and I were faced with the real issue that we may have to put limits on Brooke's use of the new "toy" as she did not want to stop! 


\section{Gretchen's Reflection}

\subsection{5pm (December 29, 2009):}

"Mom, What is that?"

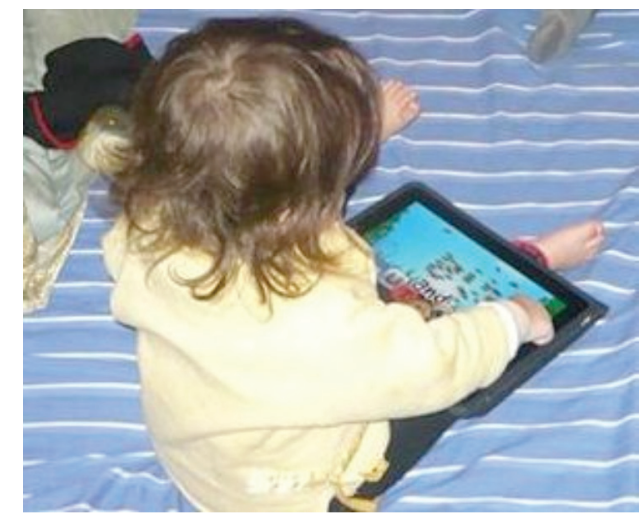

Brooke saw me using an iPad and she immediately started to use her fingers to tap and see the consequence that would happen on the screen.

This is the first moment that I actually used mobile learning technologies with a 2 year old. I was very interested in watching her using her fine motor skills by clicking on the buttons and trying different apps. The iPad was the first mobile gestural interface that we had purchased and exposed Brooke to and it was evident from day one that she could not only navigate appropriate software using the iPad, but do it easily with a high level of engagement and interactivity, especially when compared to the one way interaction of a television screen and the fine motor and cognitive developmental inappropriateness of mouse and keyboard devices. For the first time she could use her fingers as the sole interactive tool, this allowed her to control the device and after a few days Leigh and I were faced with the real issue that we may have to put limits on Brooke's use of the new "toy" as she did not want to stop! However, for the first time in my own career as an early childhood professional I felt that there was a media device that was appropriate and could be used as a wonderful adjunct to a child's learning.

\section{Leigh's Reflection}

For the first time in my own career as an early childhood professional I felt that there was a media device that was appropriate and could be used as a wonderful adjunct to a child's learning. In 2010 I was due to begin my PhD study; hence I was on the look-out for a topic.

As stated before, the use of technology and educational media with young children had been an underwhelming process and had not filled me with confidence for its use with children prior to school settings. All of this changed when my wife purchased her first iPad. Brooke was 30 months old at the time, to this point she had used many technological products designed by such toy companies as Fisher Price and Vetch, she had also watched her fair share of educational media via television stations designed for the education of young children, such as Cebeebies, appropriate DVDS and shared experiences with her Grandfather on his desktop computer. All of which we felt certainly helped her learning yet still I did not feel it was more beneficial nor grabbed her attention than the early childhood experiences I was setting up for her based on my child care background. Then along came Gretchen's iPad! Immediately Brooke gravitated to Mummies new toy and very soon we found that there was software (Apps) designed specifically for children under 5 . More than the software, it was the hardware design 
of the iPad that immediately stood out to me as an appropriate tool for young children. With my new found appreciation of technology and educational media, stemming from both Gretchen's teaching and Brooke's experiences I knew that I wanted to base my PhD on preschool aged children's use of technology and educational media. After a few weeks of discussion with my supervisors it was clear that an investigation of tablet computers was an appropriate way to move forward. In addition I wanted to survey stakeholders in the field of early childhood to see if how I felt towards technology before meeting Gretchen and viewing Brooke's experiences was how others in the field felt, that being negative and an unwillingness to embrace emergent technologies. Hence through the process of my $\mathrm{PhD}$ and recent appointment as a lecturer in early childhood at the Charles Darwin University I have been able to observe and comprehend the manner in which society is moving forward and the role that technological products have within children's future education.

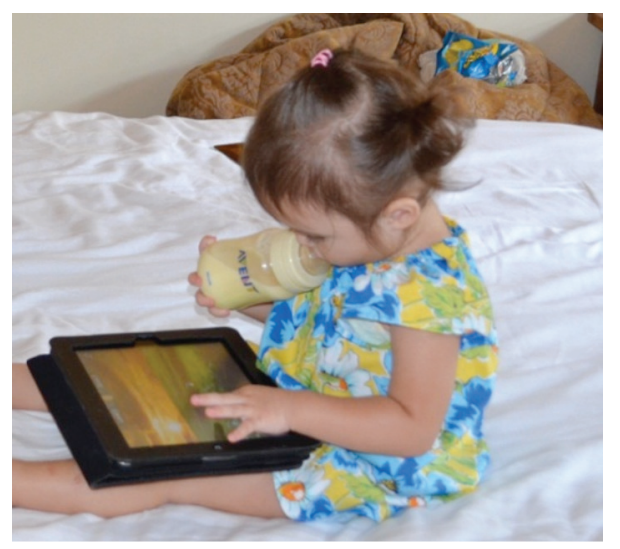

In 2012 our second child was born and by the time she was a 1 year old she had begun her own journey with the iPad and as educators, Gretchen and I had moved along a journey of reflective practice with technology that would stem into our work environment within higher education.

\section{Impact on Teaching Approaches in Higher Education}

In higher education, the importance of reflection lies in the need for educators such as lecturers to know how they taught the courses, and collect feedback for their teaching in order to improve their teaching outcomes (Hays \& Gay, 2011). Raj (2013) further stated that "maintaining and improving practice is achieved through reflection and adjustment" (p.10).

Reflective practice has always been an important component in education (Tummons, 2011), including higher education. Based upon the transformative learning theory (Mezirow, 1991), the reasons of its importance include:

a. the content reflection involves perceiving, thinking, and feeling instructional processes (Raj, 2013);

b. process reflection focuses on how teaching was performed and how well it was done (Kember et al, 1999; Raj, 2013);

c. critical reflection does not neglect psychological and sociolinguistic perspectives (Meriam \& Ntseane, 2008); and,

d. (critical reflection is essential to motive collective action for change in institutional practices (Raj, 2013). 
Moreover, in "Reflective Practitioner", Schon (1983) made an innovative and remarkable contribution of how professionals think in action. Our reflections align with his work that learning takes place both publically and privately through reflection time. Likewise, education cannot always be conducted within certain hours or certain places. It can happen anytime, with anyone and within any culture. With increasing proportion of different time allocation and rapidity of change in higher education, the "learning society" (Schon, 1983) has been developed to satisfy the needs of the nature of learning systems and the significance of learning in changing societies.

Therefore, as educators in higher education, who have an interest and expertise in Information and Communication Technologies (ICT) in education and early childhood education, we are experiencing and always using the reflective practice to collect the information about our teaching, integrating our ideas into practice as well as improving our teaching outcomes. The graduate teachers' standard also requires lecturers in education in higher education sector, who teach pre-service teachers, to not only emphasise the importance of use of technology in classrooms, but also the grasp the pedagogical knowledge and skills.

We, as higher education lecturers, found the method of reflective practice is very useful in developing our teaching pedagogies (Raj, 2013; Tummons, 2011). Although we are teaching adult students (e.g. pre-service teachers in early childhood education) in higher education, we shall still have contact with the in-direct target students (e.g., young children in early childhood) so that we can understand the final target students and can teach our own students with more developed and improved teaching pedagogies. The dynamic reflection has an important place in supporting our own identities and developing our own teaching approaches.

As higher education lecturers we now see our role not as an advocate for the use of emergent technologies and educational media, rather as someone whom through the process of shared experiences with each other and our children, detailed reading and above all a willingness to adapt long held values was able to embrace a potential learning tool that may have benefits for the field of early childhood. As higher education teachers it is our responsibility to share this knowledge, regardless of the form of this knowledge, so that our students can make up their own minds as to the appropriateness of the pedagogies we show them, which in turn will shape a new generation of learners. We must be adept at learning, to not only transform our intuitions, but also develop the "learning system" (Schon, 1983) for continuing transformation.

\section{Conclusion}

Higher education has undergone a dramatic transformation in recent years. This is evident in both the beliefs about how students learn and the type of technologies that are evolving and are available to support and enhance student learning. Higher education has undergone many modifications with the foundations of the universities shaken by new and emerging mobile technologies and by increased numbers and diversity in the student population who are demanding new learning approaches that will provide them with flexible and personalised learning. There is a need to rethink and restructure the learning experiences and explore the transformational potential of a new learning approach.

To end this paper, we would like to express our gratitude towards the opportunity to write and reflect on our knowledge in teaching approaches in higher education based upon our own personal and private learning experience. We had multiple eureka moments during our observation and reflection, which involves lots of laughter as well as tears. Throughout the journey, we do however know we are "growing" via learning, reflection and making changes. We hope via this paper that we could start to attract more researchers and early childhood educators or teachers to speak up and explore this further. 


\section{References}

Australian Institute for Teaching and School Leadership (AITSL). Australian Professional Standards for Teachers. Retrieved April 2nd, 2014, from http://www.aitsl.edu.au/.

Geng, H., Au, W., \& Yates, G. (2007) Investigation of the Supports from Teachers that Influence the Interaction between Students and Teachers. In T. Hirashima, H.U. Hope, \& S.S-C. Young (Eds.), Proceedings of the $15^{\text {th }}$ International Conferences of Computers in Education (ICCE) 2007 (pp. 205-212). Hiroshima: Asia-Pacific Society for Computers in Education.

Hays, R. \& Gay, S. (2011). Reflection or 'pre-reflection': What are we actually measuring in reflective practice? Medical Education, 45(2), 116-118.

International Telecommunication Union (2013). ICT Facts and Figures. Retrieved 21 February, 2014, from http://www.itu.int/en/ITU-D/Statistics/Documents/facts/ICTFactsFigures2013-e.pdf.

Kumber, D. Jones, A., Loke, A., McKay, J. Sinclair, K., Tse, H. Webb, C., Wong, F. Wong, M., \& Yeung, E. (1999). Determining the level of reflective thinking from students' written journals using a coding scheme based on the work of Mezirow. International Journal of Lifelong Education, 18(1), 18-30.

Meriam, S.B. \& Ntseane, G. (2008). Transformational learning in Botswanan: How culture shapes the process. Adult Education Quarterly, 58(3), 183-497.

Mezirow, J. (1994). Understanding transformation theory. Adult Education Quarterly, 44(4), 222-232.

Raj, S.J. (2013) A study on the perception of university lecturers on the use of reflective teaching practice part of peer review process, Journal of Educational Chronicle, 4(1), 9-18.

Schon, D. (1983). The Reflective Practitioner: How professionals think in action. US: Basic Books, Inc.

Tomita, D.K. (2009) Text messaging and implications for its use in education. In C.P. Ho (Ed.), Proceedings of Technology, Colleges and Community (TCC) 2009 (pp. 184-193). Hawaii: TCC Worldwide Online Conference.

Tummons, J. (2011). 'It sort of feels uncomfortable': Problematizing the assessment of reflection practice. Studies in Higher education, 36(4), 471-483. 